\title{
ELECTROCHEMICAL AND PHOTO-ELECTROCHEMICAL PROCESSES OF METHYLENE BLUE OXIDATION BY Ti/TIO, ELECTRODES MODIFIED WITH FE-ALLOPHANE
}

\author{
NICOLE LEZANA', FRANCISCO FERNÁNDEZ-VIDALL', CRISTHIAN BERRÍOS*I, \\ ELIZABETH GARRIDO-RAMÍREZ

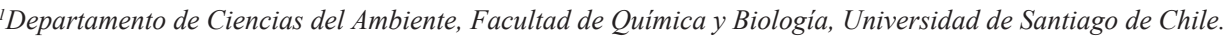 \\ Av. Libertador Bernardo O'Higgins 3363, Santiago, Chile \\ ${ }^{2}$ Centro de Investigacion para la Sustentabilidad, Facultad de Ecologia y Recursos Naturales, Universidad Andres Bello. Republica 440, Santiago, Chile.
}

\begin{abstract}
This work reports the degradation of methylene blue $(\mathrm{MB})$ on $\mathrm{Ti} / \mathrm{TiO}_{2}$ and $\mathrm{Ti} / \mathrm{TiO}_{2} / \mathrm{Fe}$-allophane electrodes in a pH 3 using $0.1 \mathrm{M} \mathrm{Na}_{2} \mathrm{SO}_{4}$ as support electrolyte SEM micrographs show a homogeneous distribution of $\mathrm{TiO}_{2}$ over the whole electrode surface forming nanotubes and nanopores. Fe-allophane modified electrode shows the formation of large-grains agglomerate on the electrode surface due to allophane, which provides a greater surface area to the electrode due to meso and micropore structures. Preliminary cyclic voltammetry show that $\mathrm{Ti} / \mathrm{TiO}_{2}$ has the typical voltammetric response due to Ti(III)/Ti(IV) pair. Diffusional problems were observed through of the film when the electrode is modified with Fe-allophane modifying the quasi-reversible process Ti(III)/Ti(IV). Different kind of methodologies in the degradation process were used: Electrochemistry (EC), Photochemistry (PC), Photoelectrochemistry (PEC) and Adsorption (Ads). These methods were developing to discard any reaction or interaction that is not of interest. On Ti/TiO with $\mathrm{PC}$ and Ads methodologies was not observed any activity to $\mathrm{MB}$ degradation showing that is not photosensitive and that the interaction between this and surface electrode is low. But with EC and PEC degradation to $55 \%$ is reached after 3 hours of electrolysis. With $\mathrm{Ti} / \mathrm{TiO}_{2}-\mathrm{Fe}$-allophane electrodes are observed a higher activity for all methodologies. The PC and $\mathrm{Ads}$ methods show that the MB degradation reaches to $\sim 20 \%$ of the initial concentration. As mentioned above, the $\mathrm{PC}$ and Ads processes no show degradation on $\mathrm{Ti} / \mathrm{TiO}$, therefore the degradation it only due to the adsorption of $\mathrm{MB}$ in/on allophane coat behaving as concentrator matrix. A lower improvement is observed with EC process when is incorporated $\mathrm{Ti} / \mathrm{TiO}_{2}-\mathrm{Fe}$-allophane is due to the barrier of the electrode surface by oxidation products. With PEC is reached the higher degradation value of $\sim 88 \%$, showing an improvement of the degradation with the presence of Fe-allophane. The results indicate that the main role of Fe-allophane on the electrode is similar to a concentrator matrix.
\end{abstract}

Keywords: $\mathrm{Ti} / \mathrm{TiO}_{2}$; Fe-Allophane; methylene blue; electrochemical and photoelectrochemical oxidation.

\section{INTRODUCTION}

The presence in the environmental of a wide range and variety of recalcitrant organic pollutants from agricultural, industrial and domestic activities made necessary to remove it through an efficient way using an environmental friendly technology. In this sense, advanced oxidation processes (AOPs) based on the combination of strong oxidants such as ozone, oxygen or hydrogen peroxide and the use of catalysts as transitions metals or semiconductors solid together with sources of radiation or ultrasound [1] have been widely proposed as a promissory way to degrade organic pollutant. The AOPs are based on the generation of a highly reactive species, which react with the most organic compounds by two principal ways: the first one is by direct electro-oxidation reaction and the other one is by indirect electro-oxidation [2]. The nature, kind and the features of the electrode material is one the most important variables to determine which of these two ways follow the degradation process.

Among the solid catalysts, the use of semiconductor such as titanium dioxide $\left(\mathrm{TiO}_{2}\right)$ has been widely studied in photochemical processes due to their potential for mineralizing a wide variety of recalcitrant organic pollutants $[3,4]$. The titanium dioxide $\left(\mathrm{TiO}_{2}\right)$ is an excellent catalyst due its photostability, high photocatalytic activity, reusable characteristics, low cost and non-toxicity $[3,5]$. For this reasons in one of the most used support material for different electrochemical (EC) and photoelectochemical (PEC) degradation processes.

The photocatalytic degradation mechanism has been extensively discussed, but there are agreements that this starts with the photogeneration of an electronhole pair (Eq. 1) due to the UV illumination on $\mathrm{TiO}_{2}$. These charged pairs might suffer a recombination or react with one water or oxygen molecules to produce reactive species (Eq. 2 and 3). The formation of hydroperoxyl radical is possible by electron transfer from $\mathrm{TiO}_{2}$ particles to molecular oxygen and consecutive protonation (Eq. 4) [6].

$$
\begin{aligned}
& \mathrm{TiO}_{2}+\mathrm{h} v \rightarrow \mathrm{e}^{-}+\mathrm{h}^{+} \\
& \mathrm{e}^{-}+\mathrm{O}_{2} \rightarrow \mathrm{O}_{2}^{--} \\
& \mathrm{h}^{+}+\mathrm{H}_{2} \mathrm{O} \rightarrow \mathrm{H}^{+}+\mathrm{HO}^{\circ} \\
& \mathrm{e}^{-}+\mathrm{O}_{2}+\mathrm{H}^{+} \rightarrow \mathrm{HO}_{2}^{-}
\end{aligned}
$$

The photocatalyts $\mathrm{TiO}_{2}$ have been used to degrade a large variety of recalcitrant organic pollutants $[2,3,7,8,9]$. It has been reported that the photocatalytic performance of $\mathrm{TiO}_{2}$ is primarily determined by its physicochemical properties such as crystal structure, particle size, surface area and microporosity. The most used $\mathrm{TiO}_{2}$ is the anatase structure due to photocatalytic properties to generate the hole-electron pair when it is irradiated with UV light by process mentioned above.

It has been widely reported that the large band gap of $\mathrm{TiO}_{2}$ limits its photoresponse to ultraviolet region $(<400 \mathrm{~nm})$ [10]. As is known, only a small proportion (approximately $4 \%$ ) of the solar spectrum corresponding to UV region $[11,12]$. Thus, the development of new efficient photo-catalysts must be developed thinking in a device that uses a higher spectra region as visible light, could involve the visible light absorption, which is $42 \%$ approximately of total solar energy. Also, many studies have demonstrating that the use of nanostructures could improve the catalytic efficiency of photo-catalysts due to large surface area and micro and mesoporosity, which could increase the adsorption of target molecules and reach higher reaction ratios $[10,11,13]$.

In this sense, there is evidence that the modification of $\mathrm{TiO}_{2}$ with other narrow band gap materials, such as iron oxide could be made possible to absorb the photons in the visible range improve the adsorption properties of the surface $[12,14,15,16]$. In the case of iron oxide studies reported that the $\mathrm{Fe}^{3+}$ ions increase the photocatalytic efficiency of $\mathrm{TiO}_{2}$ since $\mathrm{Fe}^{3+}$ can serve as shallow trapping sites and $\mathrm{Fe}$ loading on $\mathrm{TiO}$-supporting montmorillonite catalyst $\left(\mathrm{Fe}-\mathrm{TiO}_{2}-\mathrm{MMT}\right)$ for $\beta$-naphtol degradation under UV-A irradiation exhibited higher surface areas, pore volumes and extended absorption profiles through longer wavelength [5]. The mesoporous structures of the supported catalysts improved their dark adsorption capacities and degradation abilities. The existence of Fe enhances the electron transfer reaction in the catalysis. Studies photo-catalytic oxidation of 4-chlorophenol under visible ultraviolet radiation using mesoporous structures of $\mathrm{Fe}_{2} \mathrm{O}_{3} / \mathrm{TiO}_{2}$ [12], showing that the $\mathrm{Fe}_{2} \mathrm{O}_{3}$ incorporation allows the light absorption in the visible solar irradiation improvement the 4-chlorophenol oxidation. Through synthesized $\alpha-\mathrm{Fe}_{2} \mathrm{O}_{3}$ / $\mathrm{TiO}_{2}$ nanotubes [9] used for phenol degradation by heterogeneous electroFenton which is compared with $\alpha-\mathrm{Fe}_{2} \mathrm{O}_{3}$ nanoparticles and $\mathrm{TiO}_{2}$ nanotubes. They reported that the composite $\mathrm{Fe}_{2} \mathrm{O}_{3} / \mathrm{TiO}_{2}$ nanotubes electrodes were more effective, obtaining a $100 \%$ of removal efficiency after 60 minutes of treatment.

Therefore, the use of highly active photocatalyts able to absorb the solar radiation in a wide region (UV and visible range), with a porous structure and large surface area that allow a higher adsorption of the organic could be there a promissory alternative in the degradation of recalcitrant organic pollutants by electro-chemical methods. 
The use of clays minerals and $\mathrm{TiO}_{2}$ as support is a promissory alternative due that the clays exhibit large surface area and micro and mesoporosity, besides some clay are in natural association with iron species, as is the case of allophane nanoclays. Allophane is a nano-clay size mineral of a widespread occurrence in volcanic ash soils (mostly Andisols). Their unitary structure consists in hollow spherules, highly porous with a diameter in the nanoscale range $(3-5 \mathrm{~nm})$ [17]. Due allophane properties, such as, large surface area, unique structure and highly porosity, iron oxide supported allophane nanoclays with a hydrous feldspathoids structure were reported as highly active and stable in the phenol oxidation by heterogeneous Fenton reaction [18] and for the atrazine oxidation in the heterogeneous electro-Fenton process [19]. Recently, has been carried out a study with allophane-TiO nanocomposite photocatalyst to degrade trichloroethylene (TCE) under UV irradiation. The catalytic efficiency was compared with the $\mathrm{TiO}_{2}$ and the allophane-TiO mixture [20]. TCE was transformed into intermediate products, on the $\mathrm{TiO}_{2}$ during the UV irradiation further this compound was rapidly absorbed on the allophane and gradually degraded after diffusing to the $\mathrm{TiO}_{2}$. The diffusion rate on the nanocomposite was faster than on the physical mixture due to high dispersion of allophane into the $\mathrm{TiO}_{2}$. In the same way, it was also used dyedispersing allophane-titania composite electrodes to study its photoelectric conversion properties [19] and other studies the photocatalytic decomposition rate of gaseous acetaldehyde using $\mathrm{TiO}_{2} /$ allophane mixed powders with acid treatment was performance [21]. Despite of this studies that using a mixture of allophane nanoparticles and $\mathrm{TiO}_{2}, \mathrm{Fe}$-allophane/ $\mathrm{TiO}_{2}$ as efficient and stable photocatalyts for organic pollutant oxidation by electrochemical and photoelectrochemical methods have not studied yet.

Therefore, the aim of this work is study of methylene blue degradation by electrochemical (EC) and photoelectrochemical (PEC) methods using Ti/ $\mathrm{TiO}$, electrodes modified with allophane nanoclays. Methylene blue has been widely used in the dye and pigment industries and has been selected as mode pollutant due to its environmental significance, ease of analysis, and relative solubility in water [22].

\section{EXPERIMENTAL}

\section{Reagents}

All chemicals were used as received. Titanium foil $(99.7 \%)$, Nafion $\mathbb{R}$ perfluorinated ion-exchange resin and methylene blue were purchased from Sigma-Aldrich. $\mathrm{H}_{2} \mathrm{SO}_{4}(95-97 \%)$ and $\mathrm{HF}$ (48-51\%) were supplied from Merck.

\section{Preparation of Fe-allophane}

Allophane nanoclays with a theoretical $\mathrm{Si} / \mathrm{Al}$ ratio of 3.0 and similar structure to hydrous feldspathoids were synthesized by co-precipitation method [23]. The allophane nanoclays were impregnated with 6\% wt. iron oxide (Feallophane) with a wet impregnation method previously reported [17].

Preparation and characterization of $\mathrm{Ti} / \mathrm{TiO}$, and $\mathrm{Ti} / \mathrm{TiO}$, modified with $\mathrm{Fe}$ allophane electrodes.

The $\mathrm{Ti} / \mathrm{TiO}$ electrode was prepared by electrochemical anodized in presence of $0.5 \mathrm{M} \mathrm{H}_{2} \mathrm{SO}_{4}$ and $0.04 \mathrm{M} \mathrm{HF}$. The titanium plate $(6 \times 2.5 \mathrm{~cm}, 0.25$ $\mathrm{mm}$ thickness) were cleaned with acetone-ethanol (50:50) and washed with distilled water under ultrasonic bath. The anodized process was performed at controlled potential $(25 \mathrm{~V})$ with a Power Source MCP Lab Electronics M-10 QD305, under continuous stirring during 4 hours.

$\mathrm{Ti} / \mathrm{TiO}$ electrodes were modified painting the electrode surface with dispersion prepared according to method reported previously [24]. In brief, $0.5 \mathrm{~mL}$ of Nafion ${ }^{\circledR}$ perfluorinated ion-exchange resin and $4 \mathrm{~mL}$ of an aqueous dispersion containing $30 \mathrm{mg}$ of Fe-allophane were mixed and ultrasonically homogenized. The solvent was evaporated under air, in a stove at controlled temperature $\left(60^{\circ} \mathrm{C}\right)$ for $2 \mathrm{~h}$. The $\mathrm{Ti} / \mathrm{TiO}$, with $\mathrm{Fe}$-allophan modified electrode ( $\mathrm{Ti} / \mathrm{TiO} / \mathrm{Fe}$-allophane) was calcined at $460^{\circ} \mathrm{C}$ for 4 hours to activate the catalytic properties of $\mathrm{TiO}_{2}$.

The surface morphology of the electrodes was examined by scanning electron microscopy (SEM) using a Tescan Scanning Electron Microscopy (SEM).

The electrodes were also characterized by cyclic voltammetry (CV). CV were obtained with $\mathrm{CH}$-Instruments potentiostat electrochemical workstation model CHI760D. A platinum wire and saturated calomel electrodes (SCE) were used as counter and reference electrodes, respectively. The CVs were registered at $0.1 \mathrm{~V} \mathrm{~s}^{-1}$ and a solution at $\mathrm{pH} 3$ under nitrogen-saturated, using 0.1 $\mathrm{M} \mathrm{Na}_{2} \mathrm{SO}_{4}$ as support electrolyte.

\section{Methylene blue oxidation by electrochemical and photo-electrochemical} methods

Methylene blue (MB) oxidation by electrochemical method was studied using the $\mathrm{Ti} / \mathrm{TiO}$ and $\mathrm{Ti} / \mathrm{TiO}_{2}$ modified with Fe-allophane (geometric area of $20 \mathrm{~cm}^{2}$ ) as working electrode. A platinum wire and saturated calomel electrode (SCE) were used as counter electrode and reference electrode, respectively. A single compartment electrochemical quartz cell was employed using a typical three-electrode arrangement. The electrochemical oxidation (EC) was performed using a $\mathrm{CH}$-Instrument potentiostat at controlled potential $(-1.0 \mathrm{~V})$ in a mechanically stirred solution during 3 hours. The initial methylene blue concentration was $15 \mathrm{mg} / \mathrm{L}(100 \mathrm{~mL})$, prepared in $0.1 \mathrm{M} \mathrm{Na}_{2} \mathrm{SO}_{4}$ adjusted at $\mathrm{pH}$ 3 and $0.1 \mathrm{~mL}$ of the samples were withdrawn at predetermined time intervals.

Methylene blue oxidation by photo-electrochemical (PEC) process was studied in the above described conditions. UV medium pressure mercury lamp UVP Black Ray B-100 AP was positioned in front of the quartz electrochemical cells. The light source was positioned perpendicularly at $30 \mathrm{~cm}$ lighting of the working electrode.

Methylene blue concentration for both EC and PEC experiments was determined immediately by measuring the absorbance of the solution at 665 $\mathrm{nm}\left(\lambda_{\max }\right.$ for MB) using a Cary 1e UV-visible spectrophotometer.

\section{RESULTS AND DISCUSSIONS}

Characterization of $\mathrm{Ti}, \mathrm{Ti} / \mathrm{TiO}$, and $\mathrm{TiO}_{2} / \mathrm{Fe}$-allophane electrodes by SEM.

Figure 1 shows the SEM micrographs for the $\mathrm{Ti}$ base, $\mathrm{Ti} / \mathrm{TiO}_{2}$ and $\mathrm{Ti}$ / $\mathrm{TiO}_{2} / \mathrm{Fe}$-allophane electrodes. Ti base electrode (Fig.1a) shows the typica characteristic of an amorphous and non-homogeneous surface with defects generated in the laminating process and/or mechanical polishing. In the $\mathrm{Ti} /$ $\mathrm{TiO}_{2}$ electrode (Fig. 1b) it is possible to see the homogeneous size particle of $\mathrm{TiO}_{2}$ formed on Ti sheet and distributed all over the surface.
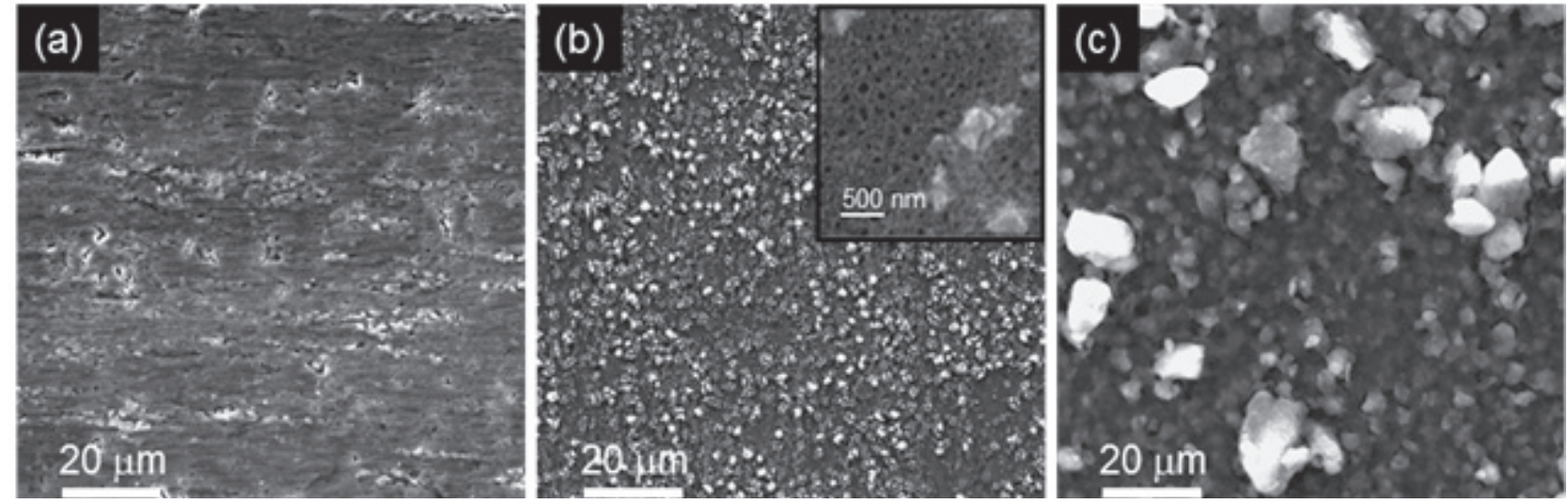

Figure 1: SEM image of (a) Ti base and (b) $\mathrm{Ti}_{1} / \mathrm{TiO}_{2}$, (c) $\mathrm{Ti} / \mathrm{TiO}_{2} / \mathrm{Fe}$-allophane electrodes used at MB degradation. 
The possible reactions that occur throughout the formation at anodized process are described by (eq. 5 and 6 )

$$
\begin{aligned}
& \mathrm{Ti}+2 \mathrm{H}_{2} \mathrm{O} \rightarrow \mathrm{TiO}_{2}+4 \mathrm{H}^{+}+4 \mathrm{e}^{-} \\
& \mathrm{TiO}_{2}+6 \mathrm{~F}^{-}+4 \mathrm{H}^{+} \rightarrow\left[\mathrm{TiF}_{6}\right]^{2-}+2 \mathrm{H}_{2} \mathrm{O}
\end{aligned}
$$

Fluoride ions present in an aqueous medium assist the formation of $\mathrm{TiO}_{2}$ nanotubes and nanopores as shown in the insert in Fig. 1b. Whereas the electrode is formed in an aggressive medium the concept for the origin of the porosity it is validated [25] due to the acid medium especially hydrofluoric acid used in anodizing. The pore formation produces a greater surface area of the electrode of $\mathrm{Ti} / \mathrm{TiO}$ compared to the $\mathrm{Ti}$ base electrode.

Finally, the electrode surface with $\mathrm{Ti} / \mathrm{TiO}_{2} / \mathrm{Fe}$-allophane (Fig. 1c) is observed rougher than the other electrodes. The Fe-allophane image shows that larger grains agglomerates are formed on the surface. This provides a greater surface area the electrode due to presence of meso and micropores in the structure. It has been noticed that the use of allophane with a higher amount of silicon in their composition produces a tetrahedral polymer with greater spaces in their structure improving the porosity of the material [26].

Characterization of $\mathrm{Ti} / \mathrm{TiO}$, and $\mathrm{TiO} / \mathrm{Fe}$-allophane electrodes by cyclic voltammetry

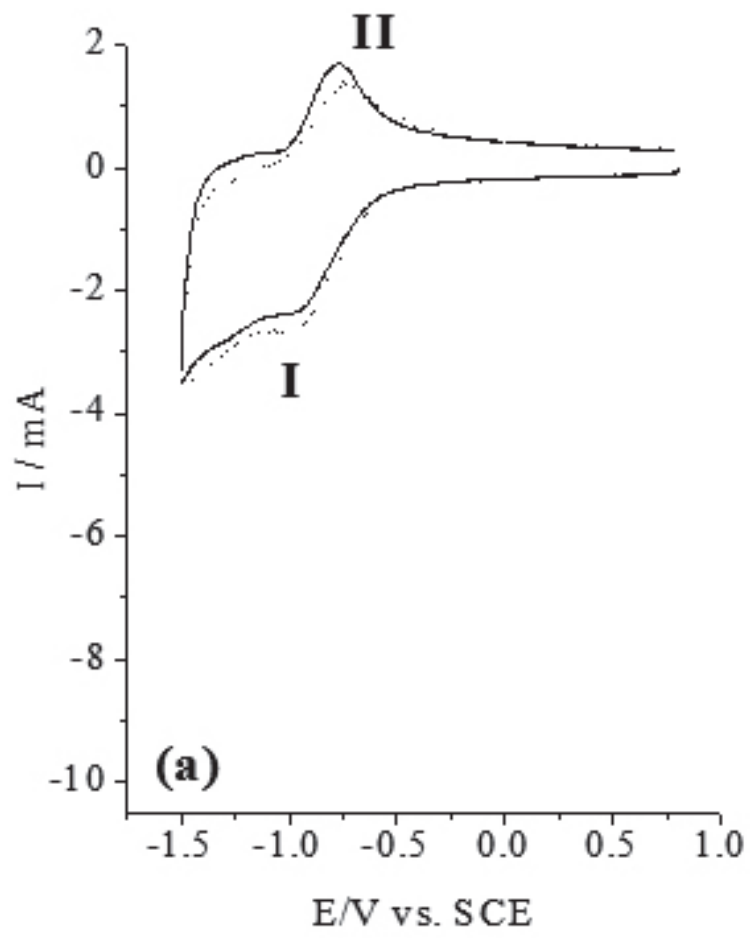

$\mathrm{Ti} / \mathrm{TiO}_{2}$ and $\mathrm{Ti} / \mathrm{TiO}_{2} / \mathrm{Fe}$-allophane electrodes were characterized by cyclic voltammetry (Figure 2). This methodology allowed clearly distinguish the redox $\mathrm{Ti}(\mathrm{III}) / \mathrm{Ti}(\mathrm{IV})$ pair characteristic of $\mathrm{TiO}_{2}$ formed on a Ti electrode (Fig. 2a peaks I and II)). The redox reaction involved is described by (eq. 7).

$$
\mathrm{Ti}^{\mathrm{III}} \mathrm{OOH} \rightarrow \mathrm{Ti}^{\mathrm{IV}} \mathrm{O}_{2}+\mathrm{H}^{+}+\mathrm{e}^{-}
$$

On the other hand, in the $\mathrm{Ti} / \mathrm{TiO}_{2}$ electrode modified with Fe-allophane was not possible to observe the couple redox $\mathrm{Ti}(\mathrm{III}) / \mathrm{Ti}(\mathrm{IV})$ (Figure 2b) because the dispersion of $\mathrm{Fe}$-allophane used to paint the electrode produce diffusional problems through of the Nafion added during the preparation of $\mathrm{Ti} / \mathrm{TiO}_{2} / \mathrm{Fe}$ allophan electrode.

Furthermore, studies of oxygen reduction reaction (ORR) was performance to determine the activity to this reaction. The ORR would be essential to produce reactive species for both $\mathrm{Ti} / \mathrm{TiO}$ and $\mathrm{Ti} / \mathrm{TiO}_{2} / \mathrm{Fe}$-allophane electrodes as indicated in equation 2 and 4 above. In the presence of $\mathrm{O}_{2}$ (Figure $2 \mathrm{a}$ and b solid line) the cyclic voltammetry of $\mathrm{Ti} / \mathrm{TiO}_{2}$ show an increase in current associated with the oxygen reduction reaction (ORR). On the other hand, Feallophane electrode the higher ORR current $(10 \mathrm{~mA})$ was associated to the presence of $\mathrm{Fe}$ centre, which it is known as reaction catalyst oxygen reduction.

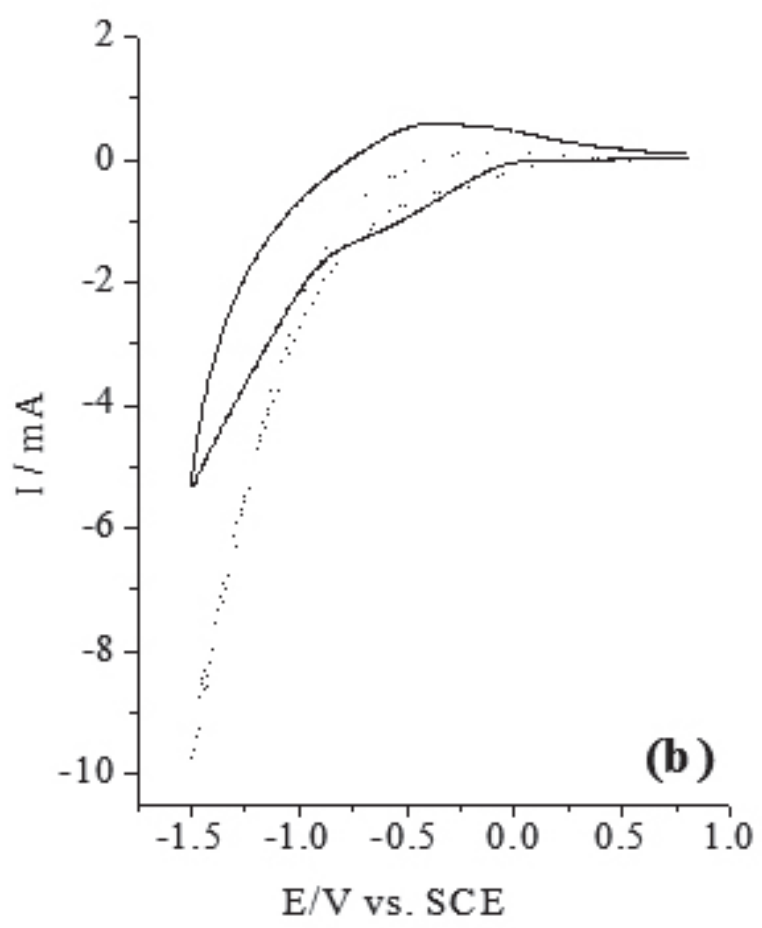

Figure 2: Cyclic voltammetry of (a) $\mathrm{Ti} / \mathrm{TiO}_{2}$ and (b) $\mathrm{Ti} / \mathrm{TiO}_{2} / \mathrm{Fe}-$ allophane. $\mathrm{O}_{2}$ (solid line) and $\mathrm{N}_{2}$ (dot line). Electrolyte solution $0.1 \mathrm{M}$ $\mathrm{Na}_{2} \mathrm{SO}_{4}$ adjusted to $\mathrm{pH}$ 3. $0.1 \mathrm{~V} \mathrm{~s}^{-1}$.

\section{Electrochemical and photoelectrochemical oxidation of methylene blue}

The MB degradation was performance with $\mathrm{Ti} / \mathrm{TiO}$ and $\mathrm{Ti} / \mathrm{TiO} / \mathrm{Fe}$ allophane electrodes by different methodologies to evaluate the occurrence of other kind of reaction, i.e., the MB degradation not occur by other way of reaction. The only paths of reaction of interest are those described by the equations 1 to 4 . The methodologies used are Adsorption on the electrode surface without the external factors mainly may occur through electric potential and electromagnetic radiation; electrochemistry using with electrolysis at controlled potential; photochemistry with mercury lamp UV light irradiation and photoelectrochemistry that is a combination between photochemistry and electrochemistry. The different reactions ways electrochemistry and photoelectrochemistry consider the formation of species highly reactive to degrade an organic substrate present in solution [27].

\section{Degradation of $\mathrm{MB}$ with $\mathrm{Ti} / \mathrm{TiO} \mathrm{O}_{2}$ electrode}

The comparison of different methodologies used is shown in Figure 3. Photochemical degradation (Fig. 3 curve •) shows a decrease in the MB concentration of $2.9 \%$, this is due to the low reactivity of MB to UV light and therefore no processes degradation were observed, which is reflected in its low value of degradation constant of $0.06 \mathrm{~min}^{-1}$ (see Table 1). Similar result is obtained for MB adsorption method (Fig. 3 curve $\boldsymbol{\nabla}$ ) with the $\mathrm{Ti}^{\mathrm{T}} \mathrm{TiO}$ electrode this is mainly because there is not interaction between the surface $\mathrm{Ti} / \mathrm{TiO}_{2}$ electrode and $\mathrm{MB}$ molecule. Both $\mathrm{MB}$ molecule and titanium dioxide have positive charge at this $\mathrm{pH}$ which produces an electrostatic repulsion and an increase of net positive charge on surface $[8,4]$.

For electrochemical (Fig. 3 curve $\boldsymbol{\Delta}$ ) and photo-electrochemical methods (Fig. 3 curve $\mathbf{n}$ ), the percentages achieved are similar between them giving 
45.8 and $43.7 \%$, respectively. These lower differences are produce by its degradation constant being for EC and PEC of $0.78 \times 10^{-3} \mathrm{~min}^{-1}$ and $0.61 \times 10^{-3}$ $\mathrm{min}^{-1}$, respectively. These results were not expected for photo-electrochemical The oxygen reduction reaction by electrochemical could produce hydrogen peroxide that has capacity to degrade the MB partially. However, regarding the photo-electrochemical reaction, it was desired to produce synergic effect between photochemical with hole-electron pair formation and electrochemical avoid the recombination.

Results obtained were similar those observed by electrochemical method since the UV irradiation has not effect on MB degradation. This might be attributed to the formation of residues during the degradation reaction which are deposited over surface as a barrier blocking the path of UV radiation to the electrode surface. Therefore, the active $\mathrm{Ti} / \mathrm{TiO}_{2}$ site where the formation of reactive species occurs is occupied by residue of reaction.

The low increased in the degradation of MB when is irradiated with UV light during electrolysis, it is due that the hole-electron pair which are charge carriers are being inactivated either by recombination among them or paralle reaction, promoted by the irradiation of UV light on the oxide film. Some authors have proposed the existence of localized zones where the holes and or electrons are deactivated by process of recombination. These sites would be associated with the morphology of the oxide film such as structural defects or impurities [29, 30].

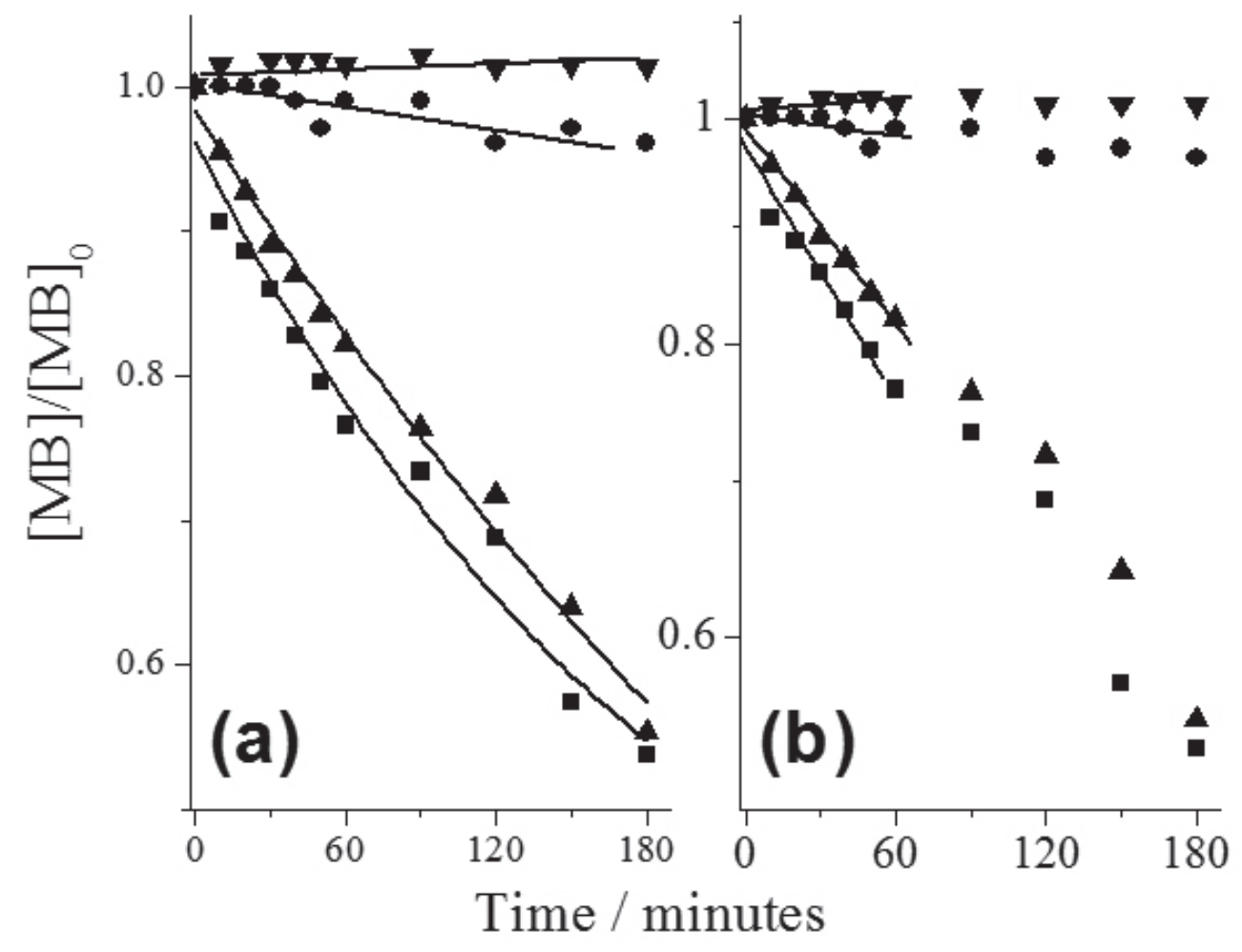

Figure 3: (a) Concentration decay of a 15 ppm MB solution and (b) pseudo first order decay for MB degradation showed in (a). ( $\Delta)$ EC, $(\bullet)$ PC, ( $\bullet$ PEC and ( $\boldsymbol{\nabla})$ adsorption methodologies using Ti/TiO electrodes at $0.1 \mathrm{M} \mathrm{Na}_{2} \mathrm{SO}_{4}$ adjusted to $\mathrm{pH} 3$.

\section{Degradation of $\mathrm{MB}$ with $\mathrm{Ti} / \mathrm{TiO} / \mathrm{Fe}$-allophane modified electrode}

Figure 4 shows the results of absorbance decrease for MB degradation on $\mathrm{Ti} / \mathrm{TiO}_{2}$ modified with Fe-allophane electrodes. This figure shows in both EC and PEC cases that there is a great decrease in the absorbance of MB to the maximum wavelength.

From absorbance values are obtained the maximum wavelength obtaining the ratio $\mathrm{A} / \mathrm{A}_{0}$ or $[\mathrm{MB}] /[\mathrm{MB}]_{0}$ which shows for the concentration decay of $\mathrm{MB}$ by EC and PEC (Figure 5).

Figure $5 \mathrm{a}$ and $\mathrm{b}$ shows that all methodologies have first-order kinetics, i.e. only it will depend on the MB concentration, showing higher efficiency of the degradation by photoelectrochemical method. The high adsorption of MB molecules close to $80 \%$ at electrode occurs by a charge interaction, since the $\mathrm{Fe}-$ allophane has a higher proportion of $\mathrm{Si}$ with respect to $\mathrm{Al}$. This would give negative charge on surface at $\mathrm{pH}$ acid and $\mathrm{MB}$ is positively charged, causing a charge attraction facilitating adsorption process. Negative surface charges that present allophane is explained by a virtual isomorphous replacement of $\mathrm{Si}^{4}$ by $\mathrm{Al}^{+3}[31]$
Adsorption is not an expected result, since the electrode could be unrecovered and certainly this adsorption affect the results observed in the other methods and the relative degradation would not be a result of MB degradation, rather of represent $\mathrm{MB}$ degradation.

Furthermore, the decrease of MB concentration by photoelectrochemical methods was higher compared to electrochemical method, this occurs because the degradation constant for PEC process $\left(1.95 \times 10^{-3} \mathrm{~min}^{-1}\right)$ is higher than EC process $\left(1.26 \times 10^{-3} \mathrm{~min}^{-1}\right)$. This can be explained if it is considered the activation of the electrode in the presence of UV light generating the electron-hole pair in $\mathrm{TiO}_{2}$ at electrode or the effect produced by Fenton iron oxides present in the electrode.

Brief, all methodologies for the electrode modified with Fe-allophane gave results of similar magnitude (Table 1). However, it is complex to point out what the process is contributing in the decreasing of $\mathrm{MB}$ concentration in each methodology. 

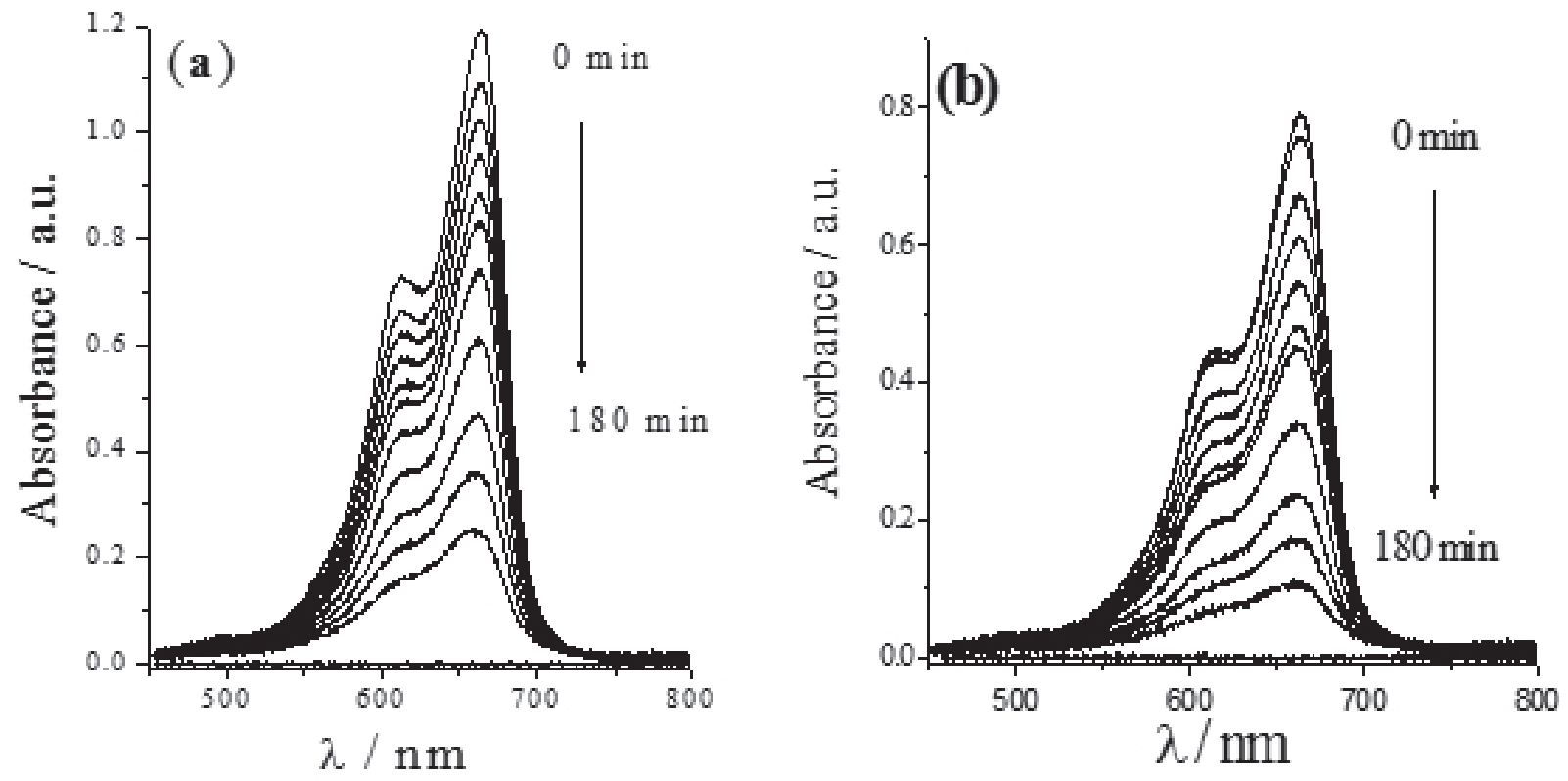

Figure 4: Absorbance decay of a 15 ppm MB solution by (a) electrochemical and (b) photoelectrochemical methods.

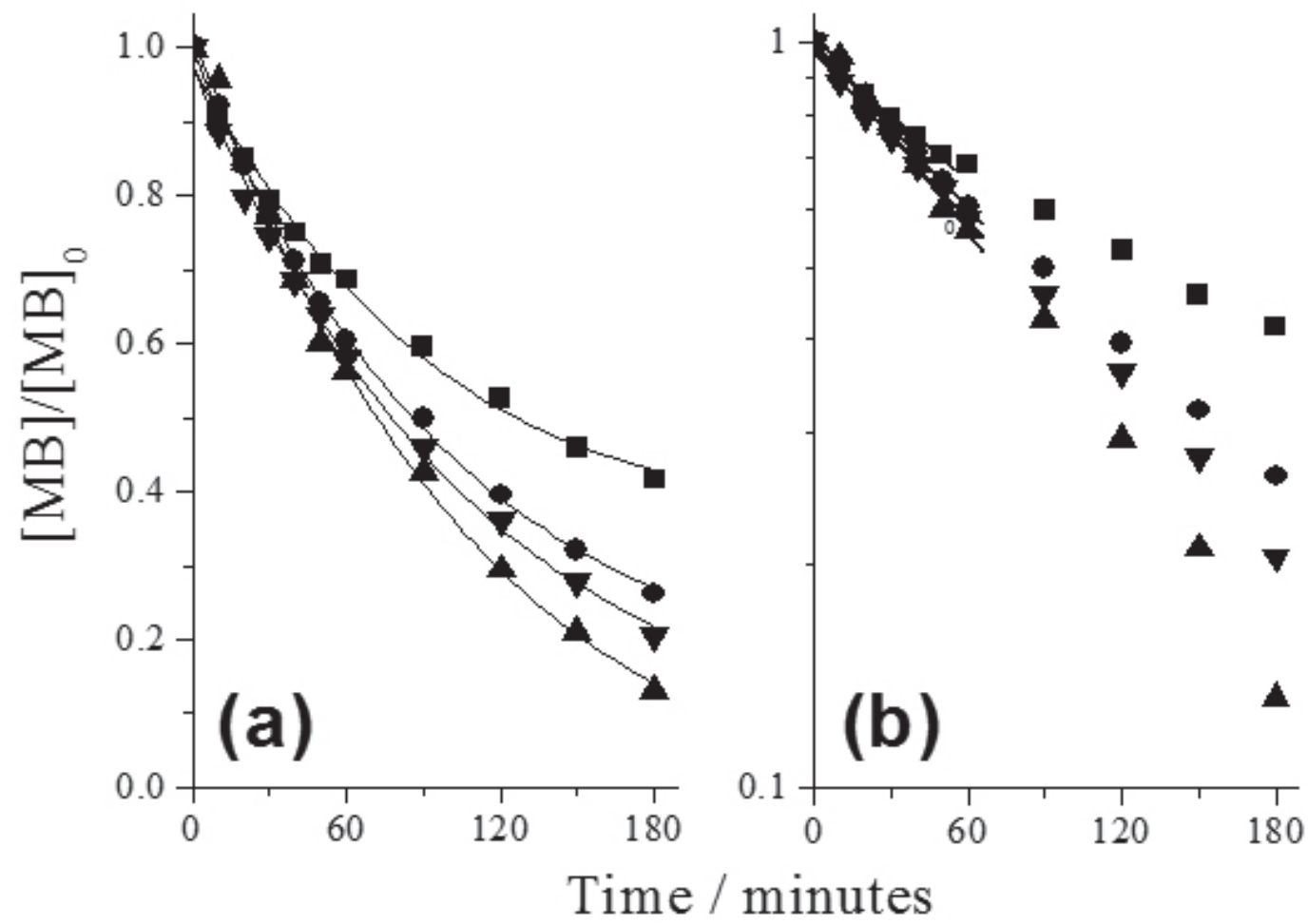

Figure 5: (a) Concentration decay of a $15 \mathrm{ppm}$ MB solution and (b) Pseudo first order decay for MB degradation showed in (a). ( $\boldsymbol{\Delta}) \mathrm{EC},(\bullet) \mathrm{PC},(\boldsymbol{\bullet}) \mathrm{PEC}$ and $(\boldsymbol{\nabla})$ adsorption methodologies using $\mathrm{Ti} / \mathrm{TiO}_{2} / \mathrm{Fe}$-allophane electrodes at $0.1 \mathrm{M} \mathrm{Na}_{2} \mathrm{SO}_{4}$ adjusted to $\mathrm{pH} 3$.

\section{CONCLUSIONS}

SEM and voltammetry studies have made possible to identify the properties and relevant characteristics in each electrode. Through SEM, the morphology of the electrodes was observed. For Ti electrode a smooth surface was seen; in the $\mathrm{Ti} / \mathrm{TiO}_{2}$ electrodes the formation of pores at surface was observed and in the $\mathrm{Ti} / \mathrm{TiO}_{2} / \mathrm{Fe}$-allophane electrodes the formation agglomerations and pores is the principal feature, attributed to the own porosity of $\mathrm{Ti} / \mathrm{TiO}_{2}$ used as a base and the structural characteristics of Fe-allophane.

Degradation of $\mathrm{MB}$ on $\mathrm{Ti} / \mathrm{TiO}_{2}$ electrodes showed a decrease of the MB concentration by electrochemical and photochemical methods reaching values of $43.7 \%$ and $45.8 \%$, respectively. With these $\mathrm{Ti} / \mathrm{TiO}_{2}$ modified Feallophane electrodes was reached the highest values of the reduction of the MB concentration.

Additionally, higher efficiency is obtained with the electrode $\mathrm{Ti} / \mathrm{TiO}_{2}$ modified Fe-allophane compared to the electrode of $\mathrm{Ti}^{-\mathrm{TiO}_{2}}$. However, the 
results show that the photoelectrochemical application produces a greater decrease in $\mathrm{MB}$ in solution, possibly associated with a combination of UV and effect the Fenton reaction due to iron oxide present in the modified electrode.

Table 1: Percentage degradation and pseudo first order constant to $\mathrm{MB}$ with $\mathrm{Ti} / \mathrm{TiO}_{2}$ and $\mathrm{Ti} / \mathrm{TiO}_{2} / \mathrm{Fe}$-allophan electrodes obtained by EC, $\mathrm{PEC}, \mathrm{PC}$ and adsorption methods. Time experiment $180 \mathrm{~min}$.

\begin{tabular}{|c|c|c|c|c|}
\hline & \multicolumn{2}{|c|}{$\mathrm{Ti}_{2} \mathrm{TiO}_{2}$} & \multicolumn{2}{c|}{$\mathrm{Ti} / \mathrm{TiO}_{2} / \mathrm{Fe}-$ allophan } \\
\hline Methods & $\begin{array}{c}\% \\
\text { decrease } \\
\text { of }[\mathrm{AM}]\end{array}$ & $\begin{array}{c}\text { Pseudo first } \\
\text { order constant / } \\
\mathrm{min}^{-1} \times 10^{3}\end{array}$ & $\begin{array}{c}\text { \% decrease } \\
\text { of [AM] }\end{array}$ & $\begin{array}{c}\text { Pseudo first } \\
\text { order constant } \\
\mathrm{min}^{-1} \times 10^{3}\end{array}$ \\
\hline EC & 45.8 & $0.78 \pm 0.09$ & 80.1 & $1.26 \pm 0.07$ \\
\hline PEC & 43.7 & $0.61 \pm 0.03$ & 86.9 & $1.95 \pm 0.09$ \\
\hline PC & 2.9 & $0.06 \pm 0.03$ & 73.1 & $1.61 \pm 0.01$ \\
\hline Ads & 0 & N.D. & 79.7 & $1.61 \pm 0.07$ \\
\hline
\end{tabular}

(*) Not determined

\section{ACKNOWLEDGEMENTS}

This work was supported by FONDECYT-CONICYT Grant 11090336 and Dicyt-USACH 21441BG.

\section{REFERENCES}

1. E.G. Garrido-Ramírez, B.K.G. Theng, M.L. Mora. Appl. Clay Sci., 47, 182 (2010)

2. Ch. Comninellis, G. Chen. Electrochemistry for the Environment. $1^{\text {st }}$ ed. New York. Springer (2009).

3. J. Pereira, V. Vilar, M. Borges, O. González, S. Esplugas, R. Boaventura. Solar Energy, 85, 2732 (2011).

4. Zangeneh, A.A.L. Zinatizadeh , M. Habibi, M. Akia, M. Hasnain Isa. J. Ind. Eng. Chem., 26, 1 (2015).

5. H. Yang, K. Zhang, R. Shi, X. Li, X. Dong, Y. Yu. J. Alloys. Comp., 413, 302 (2006).

6. A.N. Ökte, D. Tuncel, A.H. Pekcan, T. Özden. 2014. J. Chem. Technol.
Biotechnol., 89, 1155 (2014).

7. Y. Hara-kudo, Y. Segawa, K. Kimura. Chemosphere, 62, 149 (2006).

8. Y-H. Lin, T-K. Tseng, H. Chu. Appl. Catl. A-Gen., 469, 221 (2014).

9. M. Guarino, A. Costa, M. Porro. Biores. Technol., 99, 2650 (2008).

10. Y. Cong, Z. Li, Y. Zhang, Q. Wang, Q. Xu. Chem. Eng. J., 191, 356 (2012)

11. K. Nakata, A. Fujishima. J. Photoch. Photobio. C. 13, 169 (2012).

12. K. Nakata, T. Ochiai, T. Murakami, A. Fujishima. Electrochim. Acta, 84, 103 (2012).

13. B. Palanisamy, C.M. Babu, B. Sundaravel, S. Anandan, V. Murugesan. J. Hazard. Mater., 252-253, 233 (2013).

14. O. Akhavan. Appl. Surf. Sci., 257,1724 (2010).

15. F. Mazille, A. Lopez, C. Pulgarin. Appl. Catal., B. 90, 321 (2009).

16. F. Mazille, C. Schoettl, C. Pulgarin . Appl. Catal. B. 89, 635 (2009).

17. R.L. Parffit. Clay Miner., 44, 135 (2009).

18. E.G. Garrido-Ramirez, M.V. Sivaiah, J. Barrault, S. Valange, B.K.G Theng, M.S. Ureta-Zañartu, M.L. Mora. Microporous Mesoporous Mater., 162, 189 (2012).

19. E.G. Garrido-Ramírez, M.L. Mora, J.F. Marco, M.S. Ureta-Zañartu. Appl. Clay Sci., 86, 153 (2013).

20. H. Nishikiori, S. Hashiguchi, M. Ito, R.A. Setiawan. Appl. Catal., B. 147 $246(2014)$

21. Y. Ono, K-I. Katsumata. Appl. Clay Sci., 90, 61 (2014).

22. Zhang, Minghua Zhou, Xinmin Yu, Liang Ma, Fangke Yu. 2015. Electrochim. Acta, 160, 254 (2015).

23. M.L. Mora, M. Escudey, G. Galindo. Bol. Soc. Chil. Quim., 39, 237 (1994)

24. F. Fernández, C. Berríos, E. Garrido-Ramírez, N. Escalona, C. Gutiérrez, M.S. Ureta-Zañartu. J. Appl. Electrochem., 44, 1295 (2014).

25. J.M. Macak, L.V. Taveira, H. Tsuchiya, K. Sirotna, J. Macak, P. Schmuki. J. Electroceramics., 16, 29 (2006)

26. H. Khan, R. Khan, N. Matsue, T. Henmi. J. Environ. Sci. Technol., 2, 22 (2009).

27. I.M. Butterfield I, P.A. Christensen, T.P. Curtis, J. Gunlazuardi. Water Research., 31, 675 (1997).

28. M.A. Hasnat; I.A. Siddiquey; A. Nuruddin. Dyes and Pigments., 66, 185 (2005).

29. J.A. Anta. Curr. Opin. Colloid Interface Sci., 17, 124 (2012).

30. S. Palmas; A. Da Pozzo; F. Delogu; M. Mascia; A. Vacca; G. Guisbiers. J Power Sources. 204, 265 (2012).

31. G. Sepúlveda; E. Besoain. Agricultura Técnica (Chile). 43, 223 (1983). 